\title{
Performance Of CI Engine On Particulate Matter Palm Biodiesel Is Blended To Diesel In Different Proportion- A Review
}

\author{
Vinay Malviya, ${ }^{1}$ Dr. Ajay Singh, ${ }^{2}$ Prof. Sunil Patidar ${ }^{3}$ \\ ${ }^{1}$ Research Scholar, ${ }^{2}$ Prof.\& Head, ${ }^{3}$ Asst. Prof, \\ Department of Mechanical Engineering, Radharaman Institute of Technology \\ \&science, Bhopal(M.P.)
}

\begin{abstract}
As a renewable, sustainable and alternative fuel for compression ignition engine, biodiesel instead of diesel has been increasingly became popular. Biodiesel, derived from the transesterification of vegetable oils or animal fats, is composed of saturated and unsaturated long-chain fatty acid alkyl esters. In spite of having some application problems, recently it is being considered as one of the most promising alternative fuels in internal combustion engine. The aim of the present paper is to do a comprehensive review of engine performance and emissions using biodiesel from different feedstock and to compare that with the diesel. From the review it is found that the use of biodiesel leads to the substantial reduction in $\mathrm{HC}$ and $\mathrm{CO}$ emissions accompanying with the imperceptible power loss, the increase in fuel consumption and the increase in NOx emission on conventional diesel engine with no or fewer modification. However, many further researches about modification on engine, low temperature performance of engine, new instrumentation and methodology for measurements, etc., are recommended while using biodiesel as a substitute of diesel.
\end{abstract}

Keywords :Renewable, Blend, Bio-fuel, Diesel engines

\section{INTRODUCTION}

The non-sustainable non-renewable energy source has empowered the look for oil substitutes. It looks through an elective fuel. The utilization of vegetable oils as elective fills has been around for one hundred years when the pioneer of the diesel motor Rudolph Diesel originally tried shelled nut oil, in his CI motor. During the 1930s and 1940s vegetable oils were utilized as diesel energizes every once in a while, yet generally just in crisis circumstances. In 1940 first preliminaries with vegetable oil methyl and ethyl esters were completed in France and, in the meantime, speculators in Belgium were expending palm oil ethyl ester as a fuel for transports. Very little was done until the late 1970s and early 1980s when worries about high oil costs persuaded broad experimentation with fats and oils as elective fills Biodiesel is oil based energizes gotten from vegetable oils, creature fats, and waste cooking oil including triglycerides. Since the oil emergencies, the quick expanding costs and doubts concerning oil accessibility there is a developing worry for the earth and the impact of ozone depleting substances amid the last ranges. This has restored an ever increasing number of advantages in the utilization of biodiesel as a substitute for non-renewable energy sources Biodiesel is showing signs of improvement consideration as a substitute, non-lethal, biodegradable and inexhaustible diesel fuel. It is resultant from oils and fats by transesterification with alcohols. In a nation like India, where eatable oils are as yet imported, it is advantageous to investigate the probability of expending such non-eatable oils in CI motors which are not in the drill as cooking oil. Thusly, the examination on Palm oil as fuel for CI motor was embraced.

\subsection{Production}

Palm oil was transesterified with methyl liquor to acquire methyl ester of Tung oil to diminish its kinematic consistency in the scope of diesel fuel. The procedure parameters, for example, molar proportion, $\mathrm{KOH}$ focus and settling time were institutionalized to get higher recuperation of esters. Around 94 percent ester can be recuperated if the palm oil methyl liquor blend of 5:1 molar proportion is preheated for $30 \mathrm{~min}$ at $600 \mathrm{C}$ and after that responded with 1.5 percent $\mathrm{KOH}$ for $1 \mathrm{~h}$ at $600 \mathrm{C}$ and afterward permitted to make due with $24 \mathrm{~h}$ so as to get methyl ester of 4.6 centistoke (cSt) kinematic consistency. Diverse mixes of biodiesel with diesel in the extent of 10:90, 15:85 and 20:80 were readied. The trademark fuel properties, for example, kinematic consistency, relative thickness, the gross warmth of burning, cloud and pour point, blaze and flame point, carbon and fiery remains substance and all out causticity of refined Tung oil, its methyl esters and their mixes with diesel were looked at. The consequences of various fuel properties of mixes of the methyl ester of palm oil with diesel were practically like diesel.

\section{LITERATURE REVIEW}

Rubiat Mustak et al. [1] A ton of experimentation has been done to recognize a decent wellspring of option. The current examinations have found that vegetable oils can be a decent substitute for diesel fuel. However, utilizing vegetable oils specifically in a motor isn't achievable because of their high thickness and low unpredictability. Subsequently mixes of vegetable oils are utilized in motors as an option of diesel. . The impact of mixing palm oil and lamp fuel alone with diesel is contrasted and the impact of mixing palm oil and lamp oil together with diesel. So as to think about the impacts different fuel properties were estimated. This examination for the most part focus on lower warming worth (LHV) or lower calorific esteem (LCV) and thickness for different correlation purposes. 


\section{International Journal of Research in Advent Technology, Vol.7, No.4, April 2019 E-ISSN: 2321-9637 \\ Available online at www.ijrat.org}

Examining the Effect of Blending Kerosene and Palm Oil with Diesel Fuel 2018.

Allen Jeffrey et al.[2] Effectiveness of Palm Oil Biodiesel on Performance and Emission Characteristics in a Compression Ignition Engine2017. As a dangerous atmospheric devation and environmental change issues are challenging present day society manageable improvement; biofuels, biodiesel included, are among promising arrangements. Biodiesel is commonly delivered from inexhaustible vegetable oils and creature fats by means of corrosive or base catalyzed transesterification. . The mixes of palm bio diesel utilized in the test were B0(pure diesel), B15, B25. The motor execution was determined through torque, power, and explicit fuel utilization, while the discharge were determined through carbon monoxide (CO), hydrocarbon $(\mathrm{HC})$, carbon dioxide $(\mathrm{CO} 2)$, and oxides of nitrogen $(\mathrm{NOx})$ toxins. The outcome demonstrates that higher substance of palm biodiesel can diminish the emanation of $\mathrm{CO}, \mathrm{HC}, \mathrm{PM}$, and $\mathrm{CO} 2$. The ideal response conditions amid esterification are: $2.3 \%$ load of impetus, response time of $120 \mathrm{~min}$ and a response temperature of $60{ }^{\circ} \mathrm{C}$. Under these conditions, a $85 \%$ yield of biodiesel was acquired.

N. Saifuddin et al.[3] Biodiesel is accepting expanding consideration as an elective fuel due to the regularly developing interest for energy,the biodiesel-dieselbioethanol mixes may be a decent alternative. In this paper, the exploration work was completed to consider tentatively the execution and fumes outflow qualities of a $25 \mathrm{~kW}$ miniaturized scale gas turbine motor (Capstone Model C30) fuelled with biodiesel-dieselbioethanol mixes 2017. but nitrogen oxides (NOx) which added to the higher arrangement in correlation with the distillate diesel. At long last, B80E20 (80:20 of biodiesel-bioethanol) was proposed to be chosen as a perfect mixed fuel proportion to be connected in miniaturized scale gas turbine motor because of its flexibility to supplant diesel fuel, while demonstrated better execution and emanation properties when contrasted with the unadulterated oil diesel.

Kiran Raj Bukkarapu et al. [4] Palm biodiesel is mixed to diesel in various volume rates to improve certain properties. This would help in having a decent comprehension of the reliance of the diesel properties on the biodiesel extent. The properties of enthusiasm for the present work are thickness, kinematic consistency, streak point and fire purpose of the mixes which are resolved and contrasted with petrodiesel 2017. Mixes with higher palm content have higher glimmer point and flame point. Clearly, mixing intensifies the conditions and henceforth may be of no utilization when contrasted with diesel, yet when contrasted with perfect palm biodiesel, mixing helped in pulling down the thickness, consistency, fire point and blaze purpose of the last mentioned.

Neeraj Goreya et al. [5] These sources incorporate the different non-renewable energy sources like the oil, coal and the petroleum gas. The consuming of non-renewable energy sources prompted the creation of the ozone depleting substances expanding the dimensions of $\mathrm{C} 02$ in the environment. The unfavorable impacts are the a dangerous atmospheric devation and the ozone layer exhaustion 2017. The fumes discharge qualities of Tung biodiesel mixes $\mathrm{B} 10, \mathrm{~B} 50$ and $\mathrm{B} 100$ were contrasted and diesel. In light of the aftereffects of the present work, following end was drawn. The ideal conditions for most extreme yield of biodiesel generation were gotten at a molar proportion of $5: 1$, response time a hour and $1.5 \% \mathrm{KOH}$ focus. A most extreme yield of $94 \%$ was resolved. The glimmer and flame purpose of Palm seed biodiesel were resolved to be $1800 \mathrm{C}$ and $1940 \mathrm{C}$ individually which are higher than diesel fuel. The ideal conditions for most extreme yield of biodiesel creation were acquired at a molar proportion of $5: 1$, response time a hour and $1.5 \% \mathrm{KOH}$ fixation. A greatest yield of $94 \%$ was resolved.

Jalal Ghazanfari et al. [6] Biodiesel is a biodegradable fuel contains unsaturated fat methyl or ethyl esters which are ordinarily delivered by the transesterification response among the triglycerides in the vegetable oils or creature fats and a liquor, for example, methanol or ethanol. There are numerous assets of biodiesel creation. In present investigation it was chosen the palm oil to create the ethyl ester biodiesel and the constraining components for the utilization of palm oil biodiesel in a diesel motor with regards to the ASTM gauges were talked about. The best proficiency is seen in scope of $50-100 \%$ of motor burden and the best productivity is in scope of B10- B40. By and large, by considering three parameters of motor power, BSFC and motor effectiveness the B10 fuel of palm biodiesel offers the best execution, thusly it very well may be the prescribed fuel for this examination. . In present examination, biodiesel was produce through transesterification process from palm oil and after that the delivered biodiesel was mixed with diesel in various proportions $(10,20,30,40,50,60,70,80,90$ and 100 vol.\%). The properties of fuel tests were estimated by ASTM standard. The outcomes demonstrated that the thermophysical properties of palm biodiesel (Density, thickness, cloud point and blaze point) covers the ASTM norms 2017.

Azimah, R et al. [7] The point of this investigation was to decide hydrolytic dependability [acid esteem (AV)] and oxidative strength [peroxide esteem (PV) and conjugated dienes (CD)] of chose mixed oils amid potato searing. The mixed oils were set up by mixing palm oil with corn oil (POCO), sesame oil (POSO) and rice grain oil (PORBO). Mixed vegetable oils were set up in a proportion of 1 to 1 (v/v) and tried for 0, 10 and multiple times in the wake of searing potato. AV and PV were controlled by titration technique, while $\mathrm{CD}$ was resolved utilizing the spectrophotometric strategy. Expanding recurrence of oil browning added to expanded dimension of AV in every single mixed oil. PVs were expanded in all examples, with most perceptible augmentation saw in POSO, trailed by PORBO and POCO 2017.

Manjunath R et al. [8] A progressively feasible biodiesel, which likewise is biodegradable and a perfect vitality has drawn a lot of consideration and enthusiasm over the globe as of late. Unfaltering raise in the cost of oil based commodities and critically the ecological concerns, featured the need of elective powers. Biodiesel fundamentally comprises of Fatty Acid Methyl Esters (FAME), which are 


\section{International Journal of Research in Advent Technology, Vol.7, No.4, April 2019 E-ISSN: 2321-9637 \\ Available online at www.ijrat.org}

determined through transesterification of different sources, for example, vegetable oils, creature fat and so on oil preparing ventures could be practical feedstock for the biodiesel generation. They are appealing, elective feedstock for biodiesel creation The writing concentrated to research the phsico-synthetic properties of particularly palm oil ooze from POME is very potentional feedstock for biodiesel generation in term of unsaturated fat organization and peoperties. This unravels the transfer issues as well as add to the fuel requests 2017.

Hamed Bateni et al. [9] Serious natural concerns with respect to the utilization of fossil-based fills have raised awarenessregarding the need of elective clean energizes and vitality bearers. Biodiesel cleaning strategies can be grouped dependent on the idea of the procedure into balance based, liking based, layer based, response based, and strong fluid partition forms. The primary unfriendly properties of biodiesel - to be specific dampness assimilation, destructiveness, and high thickness principally emerge from the nearness of oxygen. To address these issues, a few redesigning methods have been proposed, among which synergist (hydro)deoxygenation utilizing customary hydrotreating impetuses, bolstered metallic materials, and most as of late change metals in different structures seem promising 2017.

IMOISI et al. [10] The palm oil and palm part oil are high in immersed unsaturated fats, about half and $80 \%$ individually and are esterified with glycerol. In creating nations, vegetable oils are supplanting creature fats in view of the expense and wellbeing concerns. It is consoling to realize that the utilization of palm oil as a wellspring of dietary fat does not represent any extra dangers for coronary conduit ailment when expended in sensible sums as a major aspect of a solid eating routine. In any case, oxidized palm oil initiates conceptive poisonous quality and organ lethality especially of the kidneys, lungs, liver and heart. Along these lines, oxidized palm oil ought to be maintained a strategic distance from. Before, palm oil was assaulted as "immersed" since it contains $44 \%$ palmitic corrosive and 5\% stearic corrosive, and in this way supposedly raises blood cholesterol and builds the danger of cardiovascular malady 2015.

M. A. Khote et al. [11] So the utilization of diesel and oil is upsurged. India having substantial populace, heaps of waste cooking oil is squandered. On the off chance that Waste cooking oil is utilized as biodiesel for elective wellspring of diesel, as diesel and oil are non customary wellspring of vitality. Fumes gas discharged from pressure start (C.I.) motor is a blend of numerous unfortunate constituents known as contaminations like oxides of nitrogen (NOx), $\mathrm{HC}, \mathrm{CO}$, and so forth. Unburnt hydrocarbon emanations appear to diminish with Biodiesel-diesel mixes and with unadulterated biodiesel, anyway with EGR the hydrocarbon outflows expanded. With increment in EGR rate the carbon monoxide discharges likewise expanded. For unadulterated biodiesel Brake Specific fuel utilization increments and diminishes for B10 and B20 in correlation with diesel. The primary reason of increment in BSFC values for unadulterated biodiesel its high estimation of thickness when contrasted and diesel 2016.
Ravindra A Patil et al. [12] Recent investigations uncover that expanding fuel costs and shortage of its supply have advanced enthusiasm for improvement of elective hotspots for oil fills. Vegetable oil is accepting expanding consideration each passing day as a result of fuel properties and similarity with oil based diesel fuel. In the present research work tests were directed on a four strokes, Single barrel, and D.I diesel motor with basic instruments to complete the execution and discharge tests on Diesel and different mixes of palm Straight Vegetable oil. So from the outcomes it tends to be inferred that $10 \%$ mix is considered as the best contrast with different mixes at $95 \%$ burden condition. The Engine performed best at the $90 \%$ stacking condition for Palm straight vegetable oil. The outcomes are relatively comparable for diesel fuel and this is likewise nearly comparable with the accessible writing. So the motor might be worked at $90 \%$ stacking condition for Palm straight vegetable oil. So the motor performed best for the $10 \%$ Palm oil mix at $90 \%$ burden condition 2016.

Sandeep Kumar Duran et al. [13] The correlation of fuel execution and ignition qualities of two biodiesel (Karanja biodiesel and Rapeseed biodiesel) with diesel fuel has been conveyed in direct infusion diesel motor and best one for diesel motor application was assessed. In this examination work the point by point examination on execution and ignition attributes of four stroke single chamber motor with karanja and rapeseed biodiesel and its mixes with diesel (in extents of $20 \%$ and half by volume) under different burden for example at no heap, $25 \%$, half and full burden was evaluated. At full burden KB50 (karanja biodiesel mix) has been recorded most reduced rate of weight rise. KB20 has most minimal recorded BSFC when contrasted with all others of biodiesel for all stacking condition even than diesel. KB20 was recorded with most extreme brake warm productivity of $31.072 \%$ at full burden, which is fundamentally because of 10 to $12 \%$ overabundance of oxygen and high lubing property 2015 .

B.L. Maharana et al. [14] Fossil energizes assets are persistently exhausting and these fixed stores are particularly moved in clear areas of the world. Nations like India having constrained assets of non-renewable energy source are before vitality emergency, on the grounds that $70 \%$ the unrefined oil is imported here. The test result demonstrates that the execution of diesel motor was tasteful with the utilization of biodiesel rather than unadulterated diesel. Biodiesel is a naturally companion inexhaustible diesel fuel elective. The execution qualities of the motor with unadulterated diesel and mixed diesel fuel have been thought about.

\section{CONCLUSION}

In the wake of inspecting the above writing review, it is seen that the biodiesel got substantially more consideration in view of its ecological advantages and financial just as its accessibility as normal assets. It has additionally comes to know the biodiesel expands the productivity, fumes gas temperature of CI motor and diminishing the particulate issues from fumes gases which are discharged to condition. Biodiesel created from non palatable oil common assets can recognize the utilization of eatable oil for the generation of 


\section{International Journal of Research in Advent Technology, Vol.7, No.4, April 2019 \\ E-ISSN: 2321-9637 \\ Available online at www.ijrat.org}

biodiesel. This expands its normal interest in the market of transportation segment and researchers and specialists are currently concentrating conceivable new wellsprings of non eatable oil of plant based or creature fats. Subsequent to checking on above research we can say that the palm oil is prudent and effective for the diesel motor, it has low carbon outflow examination than unadulterated diesel utilized in CI motor.

\section{REFERENCES}

[1] Rubiat Mustak, Tanjim Ahmed "Investigating the Effect of Blending Kerosene and Palm Oil with Diesel Fuel" International Journal of Scientific \& Engineering Research Volume 9, Issue 2, pp. 1271-1276 February-2018 .

[2] Allen Jeffrey.J "Effectiveness of Palm Oil Biodiesel on Performance and Emission Characteristics in a Compression Ignition Engine" International Journal of Science, Engineering and Technology Research (IJSETR) Volume 6, Issue 4,pp. 546-550 April 2017.

[3] N. Saifuddin, H. Refall and P. Kumaran "Performance and emission characteristics of micro gas turbine engine fuelled with bioethanol-diesel-biodiesel blends" International Journal of Automotive and Mechanical Engineering. Volume 14, Issue 1 pp. 4030-4049 March 2017 .

[4] Kiran Raj Bukkarapu "Effects of blending on the properties of diesel and palm biodiesel" IOP Conf. Series: Materials Science and Engineering 330 (2018).

[5] Neeraj Gorey "Characterization of Palm Oil as Biodiesel" IOP Conf. Series: Materials Science and Engineering 225 (2017).

[6] Jalal Ghazanfari "Limiting factors for the use of palm oil biodiesel in a diesel engine" Ghazanfari et al., Cogent Engineering pp. 1-16 (2017).

[7] Azimah, R. "Stability of blended palm oils during potato frying" International Food Research Journal (October 2017)volume 24, pp. 2122-2127

[8] Manjunath R "A review of global scenario of biodiesel, sources and sludge palm oil waste for the biodiesel production" International Journal of Research in Engineering and Technology. Volume 5, pp. 35-42

[9] Hamed Bateni "A comprehensive review on biodiesel purification and upgrading Biofuel" Research Journal 15 (2017) volume 15, pp. 668-690

[10] IMOISI "Palm oil, its nutritional and health implications" J. Appl. Sci. Environ. Manage. March, 2015 vol 19 pp 127-133

[11] M. A. Khote "Reduction of NOx emission \& Performance characteristics of Waste Cooking Oil from diesel engine using Exhaust gas Recirculation" International Journal of Current Engineering and Technology .pp. 156-160

[12] Ravindra A Patil "performance, emissions and combustion evaluation of ci engine using biofuel" International Journal of Science, Engineering and Technology Research (IJSETR), Volume 5, Issue 1, January 2016 pp. 119-124

[13] Sandeep Kumar Duran Karanja and Rapeseed Biodiesel: "An Experimental Investigation of Performance and Combustion Measurement for Diesel Engine"
International Journal of Scientific \& Engineering Research, Volume 6, Issue 1, January-2015 pp. 295-299

[14] B.L. Maharana "evaluation of performance of diesel engine with biodiesel" International Journal of Advanced Engineering Research and Studies.pp. 181-183 